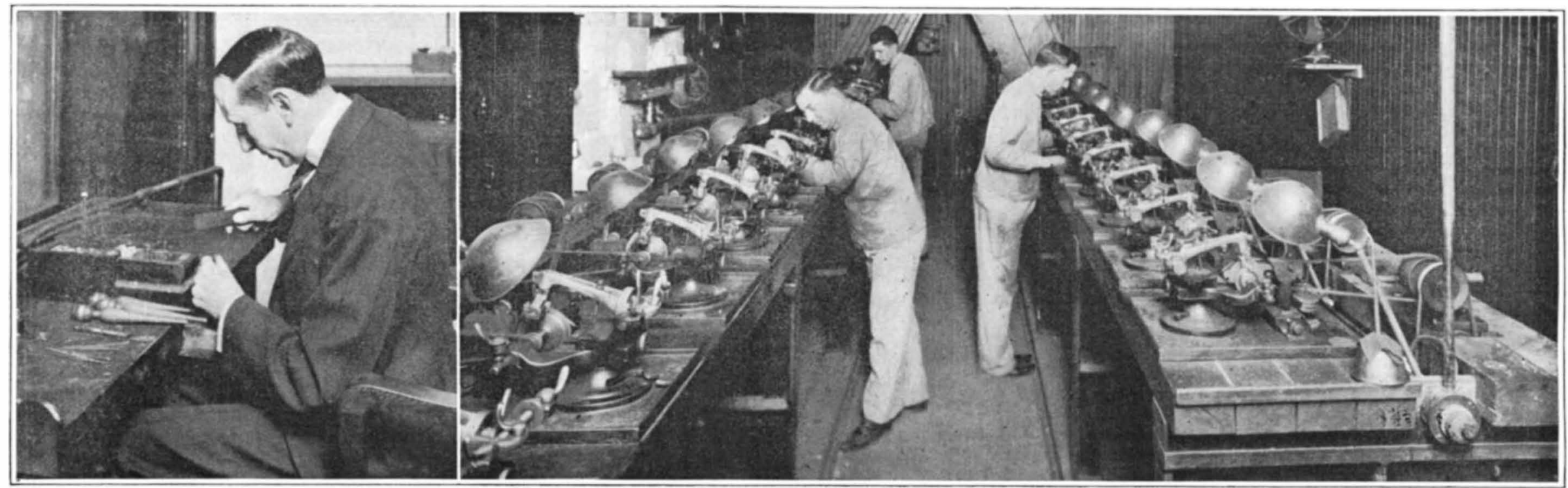

Left: Cleaver splitting the rough diamond preparatory to cutting. This calls for long experience and remarkable skill, since a slip of the tool means a very material loss in the value of the fragments. Right: The sawing room, where the dividing of a large stone is carried on with absolute precision, as contrasted with the cleaving method

Two ways in which rough stones are divided up into a number of smaller stones, preparatory to cutting

\title{
Our Diamond Industry
}

\section{How the United States Has Become the Greatest Buyer of Diamonds in the World}

\section{By Harry A. Mount} MFRICA is the greatest diamond-consuming nation
in the world. Not only do we buy more diamonds than any other people, but we buy the finest diamonds the world's markets afford. It is not surprising, then, that around this traffic has grown a curious miniature industry, whose product is of national importance.

Our diamond industry centers in New York, principally because diamonds and workmen alike have been imported through this port. There is in New York distinct "diamond district"” just above the city' famous financial district. Hundreds of firms and thousands of indivi ces in this here also are most of the important diamond-cutting plants. Nearly every diamond in this country has passed through the hands of dealers and workmen in this "diamond district."

The diamond district has taken on some of the airs of its neighbor, the financial district, for there are not only brokers, large and small, but a full-fledged curb market where the lesser tradesmen barter among themmarket
selves.

Every building in the vicinity of Maiden Lane, John and Nassau Streets has its share of diamond dealers, diamond brokers, diamond cutters, and setters. One skyscraper building is occupied exclusively by diamond interests and diamond jewelry manufacturers.

The curb market, perhaps the most picturesque feature of the diamond district, is at the corner of John and Nassau Streets, where at any time of the year and at any time of the day a group of a hundred or more men can be found standing about, apparently idling away their time, occasionally examining a paper of diamonds under a jeweler's glass. These men are all recognized diamond merchants and deal chiefly among themselves. Many of them have made a section of this curb their office for thirty years or more While it is impossible to obtain any figures on the amount of business transacted on the curb it is estimated at several millions a year. And this represents just the "tag ends" of the total business done in the diamond district.

Once all the diamonds imported into this country were cut in Holland or Belgium. Fifty years ago a Hollander named Hermann opened a diamond-cutting establishment in New York, but he did only repair work and recutting. There was another small establishment in Boston. From these small beginnings the cutting industry has grown in this country until about a thousand men are now engaged at it and they cut a good portion of the large stones sold here. Because of the high wages paid, however, nothing but stones of considerable value, where the cutting cost is comparatively small are cut here. But the workmen are the finest in the are cut here. But stone already cut in Europe is recut here because of the superior workmanship.

The whole diamond industry is so intertwined with European connections that it is well to recall here, briefly, the system which controls the world's diamond trade.

It is a well-known fact that the mines of South $\Delta$ frica supply nearly all of the diamonds of commerce. India was once the chief source of supply and a few still come from there. A few diamonds are found in
Brazil, but there are not sufficient numbers of diamonds found outside of Africa to influence the market. The South African production is controlled by a British syndicate, which thus controls 90 per cent of the world's production, and this syndicate, please take note, carefully manipulates the supply so that it is always a little in arrears of the demand.

It is a rarely accorded privilege to be able to buy direct from the syndicate. Once a buyer is on the syndicate's "list" all he can do is to apply for a "shipment" and await his turn to buy. He is required to fill out an application blank setting forth the character of the goods he wants. He is finally notified that a "sight" of the diamonds will be ready for him on a certain date. It is his privilege, then, to inspect the diamonds and refuse them if he likes. But the privilege of a "sight" is very rarely exercised. If a man rejects a shipment he is penalized by being skipped once or twice when his turn again comes around, or may even be removed from the list. lects for them. Diamonds are apportioned to the different sections of the world according to local demand for color, perfection, size and the like, and since America demands the best qualities the mines produce her buyers usually get the best.

Now most of the buyers on the syndicate's list were formerly in Amsterdam or Antwerp, and in establishing an American cutting industry some difficulty was ing an American cutting inding in finding competent workmen (Continued on page 623)

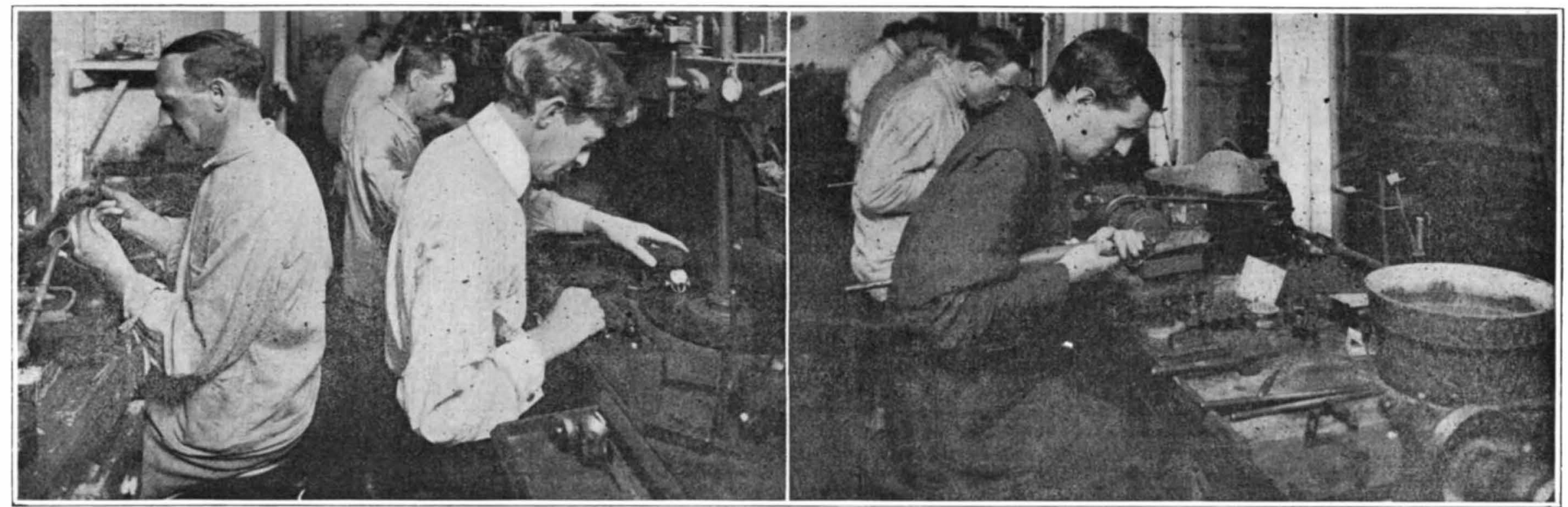

Left: The setter, shown at the left, adjusts the diamond in the holder for the polishers at the right. Polishing is done by means of close-grained semi-steel disks the working surface of which is impregnated with a mixture of oil and diamond dust. The stones are held against the revolving disk. Right: Cutting the rough stones, so as to give them their form

Two stages in the conversion of a rough, sparkless bit of crystal rock into a brilliant diamond 


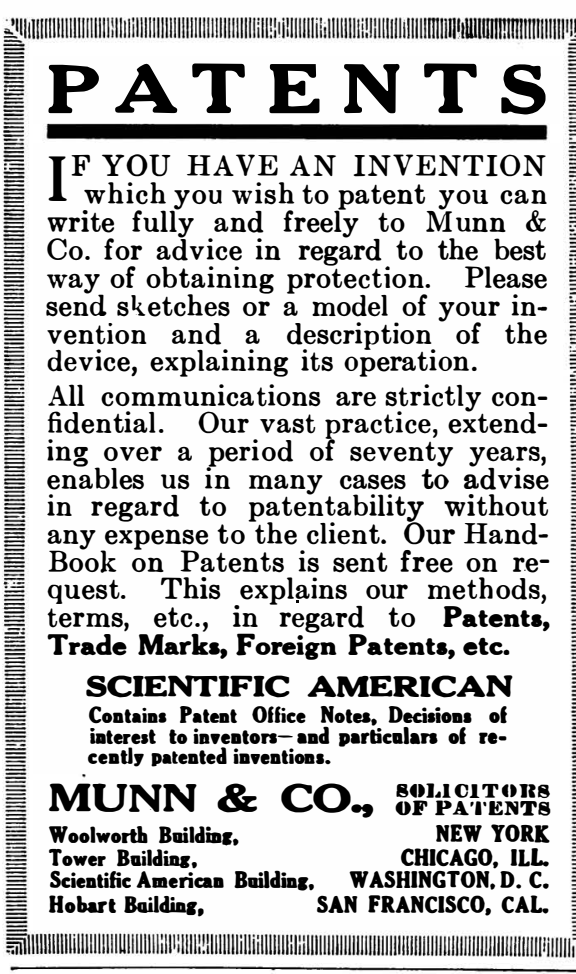

Annual Subscription Rates Scientific American Publications Scientific American (established 1845) one year
Scientific
$1876)$
American
one Postage prepaid in United States and posse
sions, Mexico, Cuba and Panama. Foreign Postage
Scientific American $\$ 1.50$ per year additional. Scientific American. Monthly $72 \mathrm{c}$ per year adCanadian Postage Scientific American 75c per year additional.
Scientific American Monthly 36 per year addiThe combined subscription rates and rates to

Remit by postal or express money order, bank

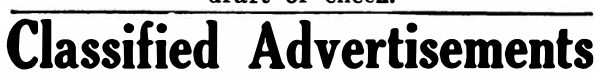

Advertising in this column is $\$ 1.00$ a line orders must be accompanied by a reme. Alt DUSINEss panied by a rem BUSINESS OPPORTUNITY
SUBST ANTIAL manufacturing corporation wants
capable men to establish branch and manage salesmen capable men to establish branch and manage salesmen more as explained. Address,
Eutaw St., Baltimore. Md.
FOR SAIE

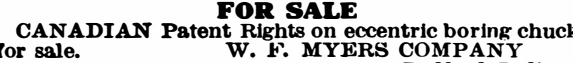
TELP WANTED PATENT Office Draftsman. State experience and
salary desired. Munn \& Co., 233 Broadway, New York
City.

You can be quickly curéd, if you

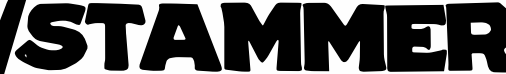
Send 10 cents for 288 -page book on stammering and
Stuttering, olts causo and Curo." It tells how

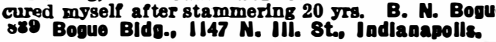

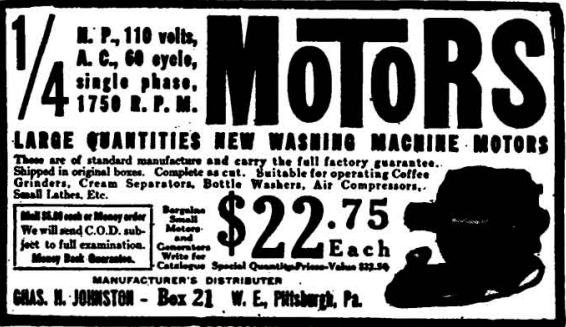

Present for Boys for Christmas SCIENTIFIC AMERICAN BOY SERIES

By A. RUSSELL BOND
Four Volum
Popular Edition.
Price $\$ 5.00$ a Set, postpaid 50c. extra.

This is a special edition which include cientific American Bo Scientific American Boy at School With the Men Who Do Things Pick, Shovel and Pluck.

Separate Folumes can only be had in regular
editions at $\$ 1.65$ net; postage $15 c$ extra so this is a real bareain to obtain an entire boxed sot for
55.50. There is no series of booke for boys a
interesting and instructive. The Set makes interesting and instructive. The Set makes a
handsome and useful Christmas present for any achool boy. They have been offcially endorse by Boy Scout

SCIENTIFIC AMERICAN PUBLISHING CO. its of honest coöperative efforts and in the value of service, not only in industr. v, but in society and in the home. We believe that this kind of education will bring about a narmonious understanding on the part of the men, of the policies of the management and the principles upon which they are founded. To show the importance attached to our education, and Industrial Relations, this department is placed at the top of our organization chart, believing that the other functions, namely, engineering, production and manufacturing no matter how perfect within ufacturing, no matter how perfect within
themselves, can be even more effective themselves, can be even more effective
when preceded by the proper education.

\section{Our Diamond Industry}

(Continued from page 614)

getting "on the list" is a long and tedious one, sometimes requiring fifteen or twenty years of persistent effort on the part of an individual.

And so not only were the diamonds and the workmen imported from Europe, but the buyers of the rough stones had to be imported, too. It is because of this fact that many of the important New York diamond merchants even today are descendants of Dutch families, and can trace a lineage of diamond merchants through a century or more.

It is said that fully 80 per cent of the diamond cutters in New York are Hollanders or the sons of Hollanders, and practically all of them are from families n which every male member is a diamond cutter. These cutters are all members of an international union which controls very closely the apprenticeships to the trade. Until very recently it was prac tically impossible to learn the trade unless the lucky applicant had some relative already in the union. The union fixes wages, but the wage any individual receives depends upon his skill and speed as a workman. A year ago, when the demand here for diamonds was phenom enal, diamond cutters in New York made from $\$ 100$ to $\$ 150$ a week.

Excepting that steam and then ele tricity have been applied to the diamon cutters' tools to replace foot-power, there has been slight progress in the art since the days of antiquity. The only really mportant invention to aid the diamond cutter during many centuries of steady activity has been the diamond saw, whic has been in use for a number of year. When the rough diamond arrives at the factory each stone is closely examined to determine the weight, flaws, and the direction of the planes of cleavage, which can only be determined by an expert. If it is decided that the stone should be divided into two or more pieces, the cleaver cements the diamond to a wooden stick and with another diamond cuts a narrow groove at the exact spot selected. A dull steel knife is inserted in this groove an a smart blow struck upon it. If this has been skilfully done the diamond divides at once and both surfaces are as smooth as if they had been polished. The process requires the greatest skill and care on the part of the cleaver for any error would cause serious loss.

The later method of sawing accom plishes the same result but with less chance of error. Half of the stone is imbedded in a small metal receptacle filled with melted soft metal and the edge of the circular bronze saw is set against it at the point selected. The saw gradually cuts its way through. It may require from three to four days to cut through a large diamond.

After the stone has been cleaved and sawed into the most economical sizes for cutting, the pieces are fastened with a strong adhesive to the demountable spindle of a small lathe. A number of diamonds are similarly mounted. A diamond is screwed on the end of a handle and is used as a tool for cutting the diamond in the lathe, being held against it by the workman. The stone used as a

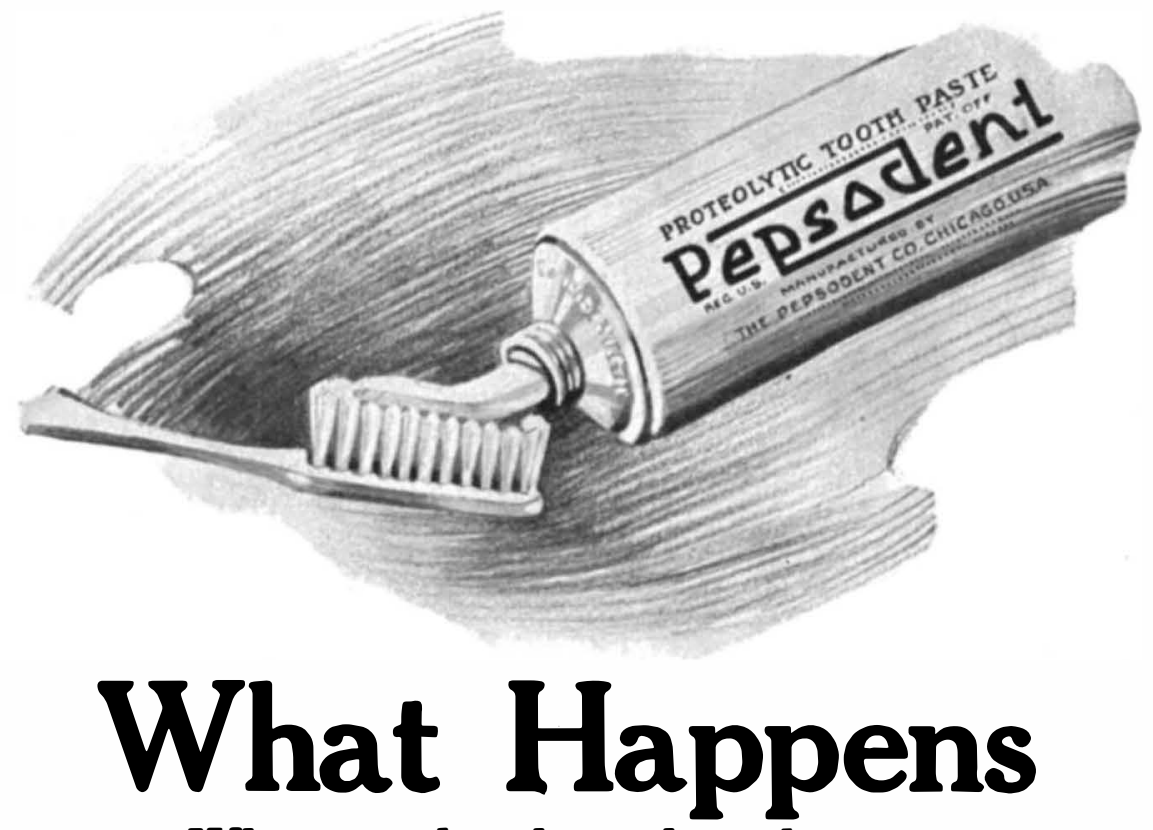

When you brush teeth in this way

Five quick effects occux when teeth are brushed in this scientific way.

Millions now get them twice a day. Leading dentists everywhere urge all to get them.

Ask us for this 10-Day Tube. It will show what these effects mean in whiter, cleaner teeth.

\section{The five effects}

Pepsodent multiplies the salivary flow. That is Nature's toothprotecting agent.

It multiplies the starch digest-

ant in the saliva. That to quickly digest the starch deposits which, if left, form acid.

It multiplies the alkalinity of the saliva. That to neutralize the acids which cause tooth decay.

Two factors directly attack the film on teeth. One keeps the teeth so highly polished that film cannot easily adhere.

These are all desired effects. They are aids to Nature which authorities approve. See how they change your tooth conditions in this ten-day test.

\section{You are welcome to this test}

A 10-day Tube of Pepsodent is sent to all who ask. It is bringing a new dental era, and we want you to know the facts.

The fight on film

Pepsodent results from many years of effort to fight film on teeth. Film is that viscous coat you feel. It clings to teeth, enters crevices and stays. The ordinary tooth paste does not end it, so film-caused troubles have been constantly increasing.

Film is what discolors, not the teeth. "Film is the basis of tartar. It holds food substance which ferments and forms acid. It holds the acid in contact with the teeth to cause decay.

Millions of germs breed in it They, with tartar, are the chief cause of pyorrhea. Thus most tooth troubles are now traced to film.

Now dental science has found ways to fight it. These methods are embodied in Pepsodent. Five years of tests have amply proved it. The highest authorities today endorse its principles. Millions now employ it.

Send the coupon for a 10-Day Tube. Note how clean the teeth feel after using. Mark the absence of the viscous film. See how teeth whiten as the film-coat disappears.

The book we send explains the reasons for its multiple effects. See and feel them, then judge for yourself how much they mean to you and yours. Cut out the coupon now.

\section{Pepsocent \\ The New-Day Dentifrice,}

A scientific film combatant, combined with two other newlyrecognized essentials. Now advised by leading dentists everywhere and supplied by druggists in large tubes.

\section{Watch them whiten}

Send this coupon for a 10-Day

Tube. Note how clean the teeth feel after using. Mark the absence of the viscous film. See how they whiten as the film-coat disappears. Cut out the coupon now.

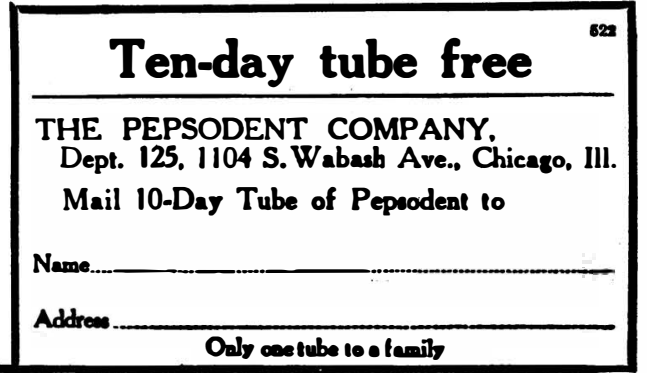

